\title{
Effective resistance of demountable shear connectors
}

\author{
A. Kozma, J. Yang \& C. Odenbreit \\ ArcelorMittal Chair of Steel Construction, University of Luxembourg, Luxembourg
}

\begin{abstract}
Steel-concrete composite construction is structurally efficient but is impossible to dismount where the floor slab is permanently connected to the steel beams through traditional welded studs. This contradicts the reuse and reduce aspects of the circular economy concept which has recently been introduced to the construction industry. Within the RFCS REDUCE project, several solutions have been proposed. Demountability of the composite beams using the proposed new shear connectors has been successfully demonstrated by pushout tests and full-scale beam tests. Both experiments and numerical simulations showed that the composite beams can develop plasticity even the demountable shear connectors in solid concrete slabs failed in a brittle way. To extend the scope of Eurocode 4 and avoid uneconomic elastic design, effective shear resistance of the demountable shear connectors was defined by using a newly developed algorithm, for the calculation of the plastic moment capacity of composite sections with partial shear connection.
\end{abstract}

\section{INTRODUCTION}

\subsection{Motivation and background}

The concept of circular economy is based on three terms: reuse, reduce and recycle. Recently this concept is becoming increasingly important in the construction industry driven by the EU target of climate neutrality by 2050 .

Steel-concrete composite construction is structurally efficient and widely adopted. However, in current design it is not dismountable and the separation of materials is labor- and costintensive. This makes the recycling process complicated and decreases the reuse efficiency of materials. The EU RFCS funded project - REDUCE targeted this issue and explored design for deconstruction and reuse in commercial and residential buildings using steel-based hybrid structural systems. Specifically, novel types of demountable shear connectors used in composite beams have been developed and tested in the form of push tests, (long-span) beam tests. The use of normal bolts as shear connectors have been considered a few decades ago but only for retrofitting purposes. More recently, attention has been paid into deconstruction aspects and replacing welded studs by bolted connectors. Pavlović M. et al. (2013) provided respective analysis on bolted connectors against welded studs through push tests. Ataei A. et al. (2016) and Liu et al. (2017) investigated the high-strength friction-grip bolts used as shear connectors in beams with precast concrete slabs.

The scope of this paper is to present the development of effective shear resistance of the demountable shear connectors developed at the University of Luxembourg (UL) within REDUCE for the calculation of the plastic moment capacity of composite sections with partial shear connection. The push tests showed that the developed shear connection systems have six-millimeter deformation capacity, which is required by Eurocode 4 for a headed stud to be considered as ductile. However, the tests at UL showed that the general behavior of the 
demountable shear connections used in solid slabs is significantly different from the traditional solutions with welded studs. They did not show a ductile behavior at failure but failed in a brittle way. Consequently, Eurocode 4 does not enable the use of equidistant shear connector spacing and the design needs to be performed using fully elastic analysis which is uneconomic and hinders the practical application of demountable and reusable composite structures. As a result, an effective shear resistance was defined with the help of a newly developed algorithm, considering that composite beams can develop plasticity even if non-ductile shear connection is applied. It was shown that with the usage of the effective shear resistance, the Eurocode 4 rules for the calculation of the plastic moment capacity of composite sections with partial shear connection remain applicable; and therefore, the developed algorithm enables the extension of the code for demountable shear connections. In this way, the benefits of composite construction can be maintained while providing the possibility of reuse.

\subsection{Demountable shear connections}

In the frame of the conducted research, two types of shear connections (Figure 1) have been investigated at UL. They offer good level of reusability of the concrete slabs as the bolts connecting the slab and the steel beam are easily replaceable if thread damage occurs during service or dismantling/reassembling of the flooring system. Both types used prefabricated concrete deck elements, which were connected to a steel beam with the help of bolted shear connectors. The first type used two M20, Gr. 8.8 bolts coupled with the help of a mechanical coupler device of grade 10.9. One bolt and the coupler device were fully embedded in the deck element and the second bolt were placed through a predrilled hole in the flange of the steel beam. The second type was a through bolt connection that used pretensioned M20, Gr. 8.8 bolts placed inside an encased steel cylinder. The figure below shows the schematic drawing of the two types of connections. The detailed description of the connections can be found in the $\mathrm{PhD}$ thesis of Kozma, A. (2020).

\section{EXPERIMENTAL CAPAIGN AND NUMERICAL SIMULATIONS}

\subsection{Push-out tests}

Five series of push-out tests were carried out on different variants of the connectors based on Eurocode 4, Annex B. The deck elements were completely solid slabs in three series, while two series used profiled steel sheeting with a solid strip around the connectors (see Figure 1). No difference in the results could be observed between these two different types of deck. This way, it was possible to reduce the weight of the slab elements without compromising the load

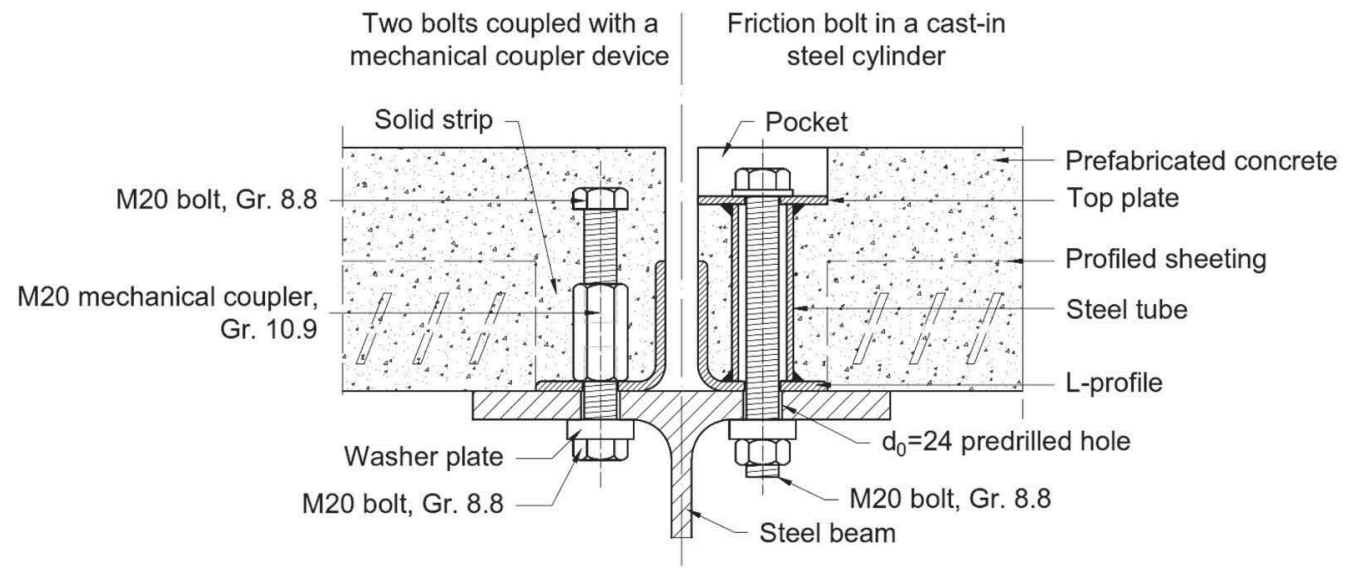

Figure 1. Left: coupled bolts (P15.1); right: friction bolt in a cast-in cylinder (P3.3). 
bearing capacity. Bolt shear failure occurred in each test after reaching the maximum shear capacity of the bolts. No plastic plateau, nor any significant descending branch was observed, all specimens failed in a brittle way. Nonetheless, all of the tested connections had a slip capacity that is greater than six millimeters, which is the slip capacity requirement for ductile shear studs given by EN 1994-1-1 (CEN 2004), Clause 6.6.1.1 (5). Figure 2 shows the load-slip measurements and the average load-slip curves of the two types of connections. As is shown, these load-slip curves differ from the load-slip curves of traditional headed studs that generally reach their ultimate capacity around $1 \mathrm{~mm}$ slip and can maintain that load until at least $6 \mathrm{~mm}$ (Kozma, A. et al. 2019).

\subsection{Beam tests}

Each type of shear connection was also investigated by full-scale beam tests. Two 6-meter-span demountable composite beams were fabricated. Each specimen comprised of an IPE 360 steel beam and two prefabricated concrete deck elements. The demountable shear connectors were placed in pairs equidistantly along the length with a longitudinal spacing of $600 \mathrm{~mm}$ and a transversal spacing of $100 \mathrm{~mm}$. The beams were subjected to 2-point loading. The loading regime included an incremental cyclic loading followed by loading up to failure. During the tests, the force and the displacement values were continuously recorded. Both beams behaved elastically before reaching a deflection level of $\mathrm{L} / 300$, which is a generally accepted criterion in the serviceability limit state. The beams reached their ultimate capacity at deflection levels greater than L/50. A certain plastic plateau could also be observed on the load-deflection curves. In other words, the beams behaved in a ductile way despite of the non-ductile nature of the applied shear connections.

\subsection{Modelling, validation and parametric studies}

The beam tests were reproduced numerically by 3D nonlinear simulations using ABAQUS 2017. The shear connectors (considering nonlinear load-slip behavior) were modelled as fasteners, which are point-based, mesh-independent connector elements. The shell element (S4R) was adopted and the global mesh density was $50 \mathrm{~mm}$. The concrete ribs and the profiled sheeting were neglected due to their insignificant contribution to the beam capacity. Tested material properties were used with concrete damaged plasticity model for concrete and a tri-linear model for steel considering a descending branch. Boundary and loading conditions of the experimental tests were replicated in the FE model. The numerical models were capable of capturing the load-deflection response, occurring slips and observed damages. A total of 112 simulations were performed for the parametric studies, considering the beam length, shear connection type, material grades, steel profiles and the distributions of connectors. The results were used for the evaluation of the developed calculation method, which will be presented in Section 3. Figure 3
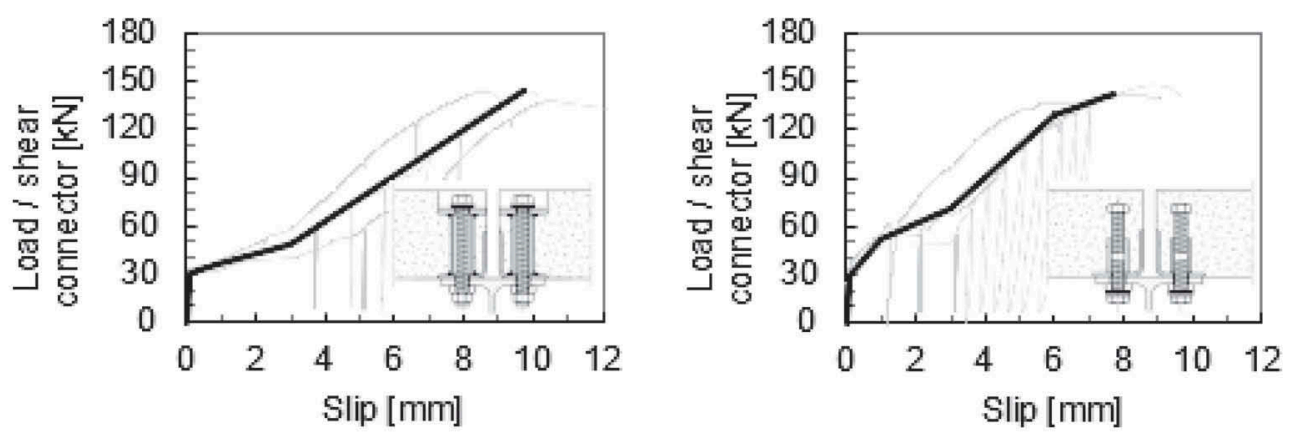

Figure 2. Load-slip relationships and the average load-slip curves of two types of connections. 


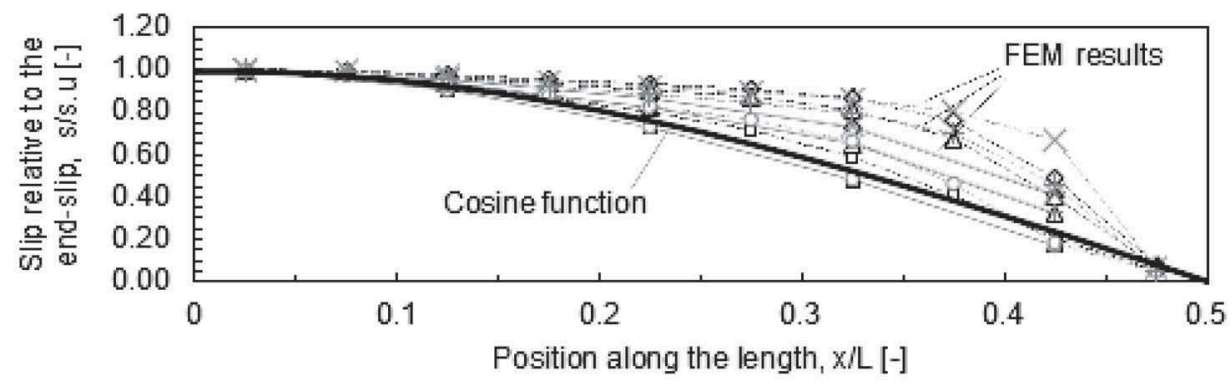

Figure 3. Slip distributions in comparison with a cosine function.

shows an extract of the results. It shows the slip distributions for twelve 6-meter-span beams using different amounts and types of shear connectors. The presented slip values correspond to the load level at which the plastic moment capacity is reached, and are shown relative to the end slip.

\section{EFFECTIVE SHEAR RESISTANCE}

From the previous section, it is obvious that the load-slip behavior of the demountable shear connectors is fundamentally different from the one of welded shear connectors. The slips could result in possible redistribution of the longitudinal shear depending on the flexibility and the deformation capacity of the connection. Therefore, the shear force that the flexible connectors can transfer needs to be evaluated for the moment capacity of a composite beam.

It is known that the occurring slip at each shear connector along the beam length should varies so as the shear force. Some researchers (Lawson R.M. et al. 2017, Hanswille, G. \& Schäfer, M. 2007) assume a cosine shaped slip distribution along the length for a simply supported beam with linear load-slip curve of the shear connectors. Theoretically, this would correspond to a sinusoidal moment diagram but it is also a reasonable approximation for uniformly loaded beams with a second order moment diagram. Beyond the elastic limit, further elastic deformations occur and plastic strains start to develop in the 'plastic zone'. The slip due to plastic deformation is constant in the elastic part of the beam (Bärtchi, R. 2005). The total slip can then be determined as the sum of the slips due to elastic and plastic deformations.

Nonetheless, the slip due to plastic deformation is difficult to quantify without the help of numerical simulations. Figure 3 demonstrated that the assumption of a cosine slip distribution is reasonable for the demountable shear connectors. And thus, the cosine function is adopted in this paper. It is important to point out that the more the bending moment diagram differs from a sinusoidal shape, the less accurate the procedures developed in this paper will become.

When the end slip $\bar{s}$ at the maximum load level of the composite beam (i.e. the beam reaches its plastic moment capacity) is set, the occurring slip at each shear connector along the beam span and then the corresponding shear force could be worked out based on the cosine function and the load-slip relationship of the shear connector. In EN 1994-1-1, Clause 6.6.1.1(5), a minimum $6 \mathrm{~mm}$ slip capacity is required for ductile shear connection. In consistent with this requirement, the end slip $\bar{s}$ is taken as $6 \mathrm{~mm}$ in this paper.

For a composite beam with concrete deck placed on the top flange of the beam, the compression force in concrete can be expressed as:

$$
N_{c}=n_{r} \sum_{i=1}^{n_{p}} P_{s c, i}
$$


where $n_{\mathrm{r}}$ is the number of shear connectors in a row, $n_{\mathrm{p}}$ is the number of shear connector rows placed within the critical length, $P_{\mathrm{sc}, \mathrm{i}}$ is the shear connector force at each shear connector. The determination of $P_{\mathrm{sc}, \mathrm{i}}$ relies on the assumed slip distribution function and the respective load-slip relationship of the chosen shear connector.

Noted that some conditions and assumptions applies as follows: 1) the beam is simply supported and subjected to a positive bending moment, 2) the steel beam section is Class 1 or 2 according to EN1993-1-1, 3) the section is symmetric to the vertical axis, 4) the shear connection is distributed equidistantly along the length, 5) the curvature of the composite beam under failure conditions is large enough to enable the assumption of a plastic stress distribution in the cross-section.

To simplify the calculations for $N_{\mathrm{c}}$, the average shear connector force, i.e. the effective shear resistance, $P_{\mathrm{R}, \mathrm{eff}}$, was proposed:

$$
P_{R, e f f}=\frac{\sum_{i=1}^{n_{p}} P_{s c, i}}{n_{p}}
$$

The compression force, $N_{\mathrm{c}}$, in the concrete can then be calculated by multiplying the number of shear connectors, $n$, between the support and the position of the maximum bending moment (critical length) by the effective shear resistance, $P_{\mathrm{R}, \text { eff }}$, of the connector:

$$
N_{c}=n \cdot P_{R, e f f} \leq N_{c, f}
$$

where $N_{\mathrm{c}, \mathrm{f}}$ is the maximum possible compression force in the concrete slab.

For easy calculation of the effective shear resistance, $P_{\mathrm{R} \text {,eff }}$, a parameter $k_{\mathrm{flex}}$ that represents the ratio of $P_{\mathrm{R}, \text { eff }}$ to the shear force in the last shear connector $\bar{P}$ was introduced:

$$
k_{f l e x}=\frac{P_{R, e f f}}{\bar{P}}
$$

The factor $k_{\text {flex }}$ depends on: 1) the load-slip curve of the shear connection, 2) the number of shear connector rows $n_{\mathrm{p}}$ on the critical length. The value of $k_{\text {flex }}$ can be calculated using the load-slip curves of the tested demountable shear connectors presented in Figure 2, with the following assumptions: i) the end slip is set as $6 \mathrm{~mm}$ when the plastic moment resistance is reached, ii) the slip distribution can be described by a cosine function, iii) the shear connectors are placed equidistantly. From Figure 4 , it is shown that the more shear connector rows $\left(n_{\mathrm{p}}\right)$, the lower the value of $k_{\text {flex }}$. However, the difference in the values of $k_{\text {flex }}$ between 4 rows and 30 rows is relatively small. For the tested shear connections, its value varies between 0.69 to 0.81 . As a simplification, it is proposed to use the number that corresponds to $n_{\mathrm{p}}=6$. This means, that when determining the average shear connector force $P_{\text {Reff }}$, we assume that only six pairs of shear connectors are placed on the critical length. The advantage of this simplification is that $k_{\text {flex }}$ now only depends on the load-slip curve, i.e. it became a shear connection specific parameter. For shear connection type P3.3 and P15.1, the value of $k_{\text {flex }}$ is 0.756 and 0.762 , respectively. The effective shear connector resistance can be determined as:

$$
P_{R, e f f}=k_{f l e x} \cdot P_{R, 6}
$$

where $P_{\mathrm{R}, 6}$ is the shear connector resistance at $6 \mathrm{~mm}$ slip.

After this point, the calculation procedure is analogous to the Eurocode 4 method for the determination of the plastic moment resistance of composite beam with partial shear connection. The plastic stress distribution and the location of the neutral axes can be determined from the equilibrium equations of compressive and tensile forces from the concrete and steel beam elements; and the moment resistance $M_{\mathrm{pl}, \eta}$ from the moment equation. The flowchart of 


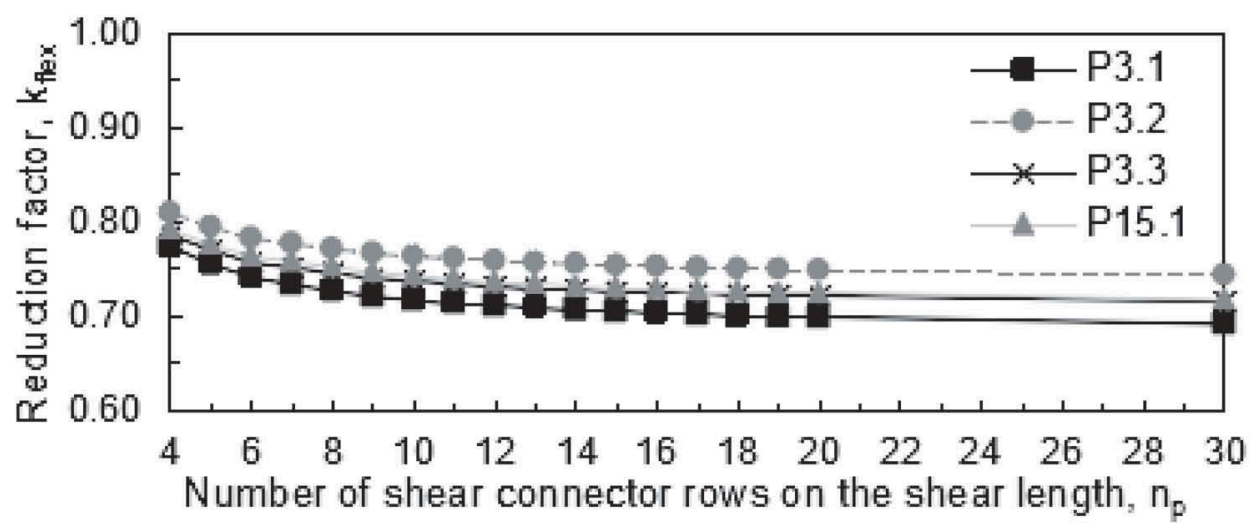

Figure 4. Reduction factor $k_{\text {flex }}$ depending on the number of shear connector rows.

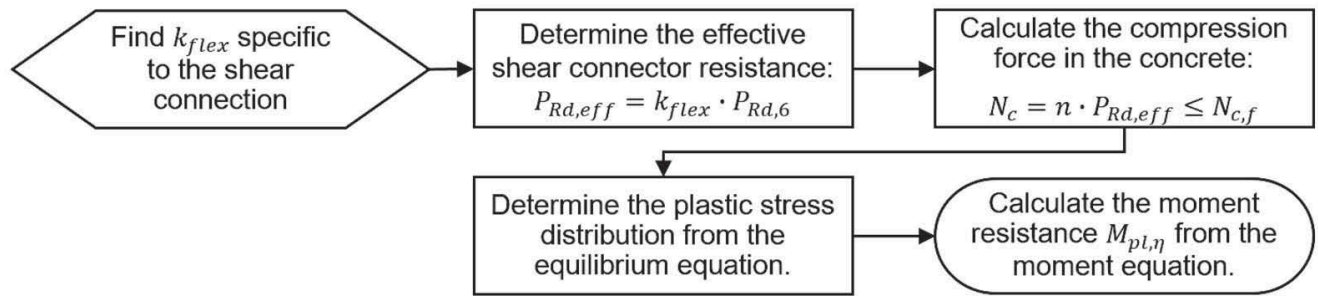

Figure 5. Simplified algorithm for the determination of the plastic moment resistance of composite beams with non-ductile shear connection.

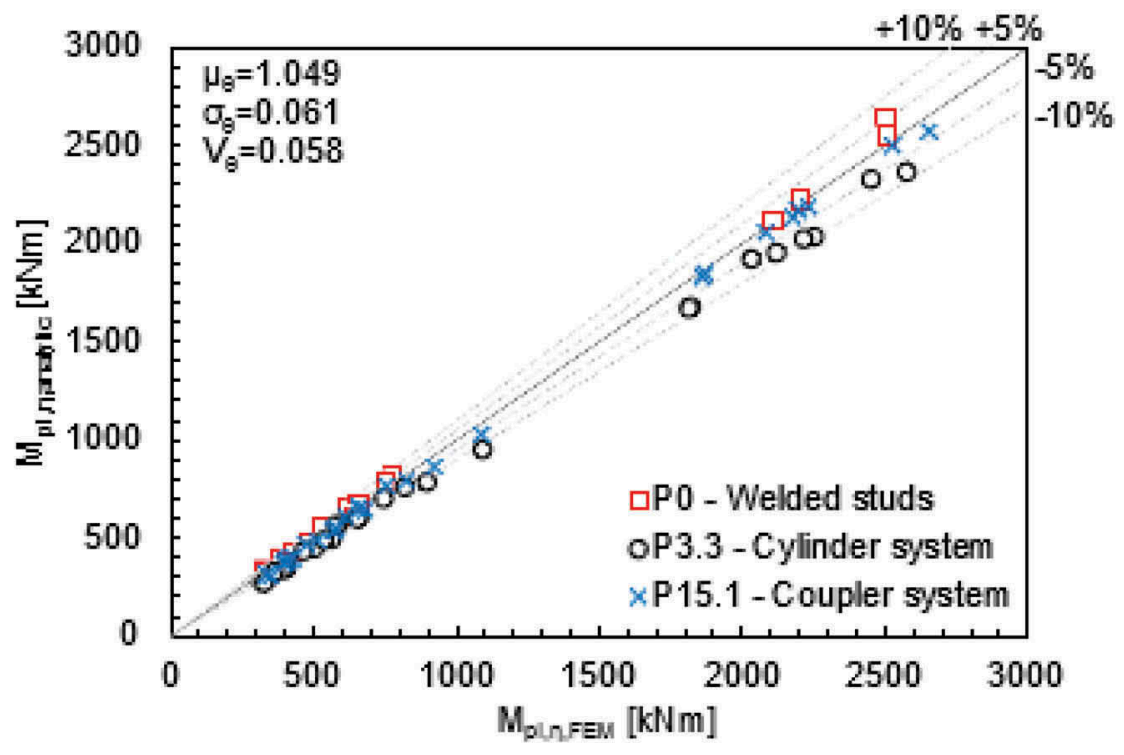

Figure 6. Comparison of the analytically and numerically obtained resistance values. 
the simplified calculation method is presented in Figure 5. The accuracy of the algorithm depends on the initially assumed end slip (6 $\mathrm{mm}$ in this paper) and slip distribution function (cosine function for simply supported beam with uniformly distributed load). The approximation of the occurring end slip is complicated at the ultimate limit state. However, conducted experimental and numerical investigations show that the aforementioned assumptions are reasonable. The calculated moment resistance values using the simplified algorithm were compared to the numerical simulation results. The mean value of the uncertainties, the standard deviation and the coefficient of variation is $\mu_{\theta}=1.049, \sigma_{\theta}=0.061$ and $V_{\theta}=0.058$, respectively. The comparison of the experimentally and numerically obtained resistance values is presented in Figure 6. Based on the comparison, it was concluded that the simplified algorithm is applicable for the determination of the plastic moment resistance of composite beams with the presented demountable shear connection.

\section{CONCLUSIONS}

The general behavior of the demountable shear connectors presented in this paper is fundamentally different than that of a welded stud. The shear connectors failed in a brittle way (classified as non-ductile shear connectors which does not exhibit an ideal plastic plateau) while allowed the development of plasticity of a composite beam. As a result, the basic assumptions for ductile studs in Eurocode 4 is not applicable. A simplified algorithm was therefore developed for the calculation of plastic bending resistance of a composite beam with the demountable shear connectors, which is analogous to the current Eurocode 4 design procedures. This algorithm adopted the proposed effective shear resistance and reduction factor for non-ductile shear connectors, with assumed end slip of $6 \mathrm{~mm}$ and a cosine function of the slip distribution of shear connectors along the beam span. From the comparison of analytical and numerically obtained results, it was shown that the simplified algorithm is able to produce plastic moment resistance $M_{\mathrm{pl}, \eta}$ values with acceptable accuracy.

\section{REFERENCES}

Ataei, A., Bradford, M.A. \& Liu, X. 2016. Experimental study of composite beams having a precast geopolymer concrete slab and deconstructable bolted shear connectors. Engineering Structures, 114, 1-13.

Bärtschi, R. 2005. Load-bearing behaviour of composite beams in low degrees of partial shear connection. PhD Thesis, Zürich: ETH Zürich Research Collection. https://doi.org/10.3929/ethz-a-004906133

CEN. 2004. EN1994-1-1. Eurocode 4: design of composite steel and concrete structures - part 1-1: general rules and rules for buildings. Brussels, Belgium.

Hanswille, G. \& Schäfer, M. 2007. Simplified method for the determination of the influence of flexibility of shear connection on deflections of composite beams and slim-floor systems (in German). Stahlbau, 76(11),845-854.

Kozma, A., Odenbreit, C., Braun, M.V., Veljkovic, M. \& Nijgh, M.P. 2019. Push-out tests on demountable shear connectors of steel-concrete composite structures. Structures, 21, 45-54.

Kozma, A. 2020. Demountable Composite Beams: Analytical Calculation Approaches for Shear Connections with Multilinear Load-Slip Behaviour. Doctoral Thesis, University of Luxembourg. http://hdl. handle.net/10993/44263

Lawson, R. M., Lam, D., Nellinger, S. \& Aggelopoulos, E.S. 2017. Serviceability performance of steel-concrete composite beams. Proceedings of the Institution of Civil Engineers - Structures and Buildings, 170(2): 98-114.

Liu, X., Bradford, M.A. \& Ataei A. 2017. Flexural performance of innovative sustainable composite steel-concrete beams. Engineering Structures, 130, 282-296.

Odenbreit, C. \& Kozma, A. 2019. Dismountable Flooring Systems for Multiple Use, BAMB, Brussels, Belgium.

Pavlović, M., Marković, Z., Veljković, M. \& Budevac, D. 2013. Bolted shear connectors vs. Headed studs behaviour in push-out tests, Journal of Constructional Steel Research, 88, 134-149. 